ume thus extends the work begun by Roth and brings it down to the year 1900, while appendices which will be issued from time to time will serve to keep the work up to date. It is, however, much more valuable than Roth's tables in that the analytical work embraced by it is of a better average quality than the older analytical work and because the analyses collected are not all thrown together irrespective of quality, but are divided into two classes; the 'Superior Analyses,' which judged by the various criteria discussed are believed to be correct, and 'Inferior Analyses,' which are of such a character that deductions based upon them must be regarded as erroneous.

The number of analyses published during the seventeen years in question and which are thus included in Dr. Washington's book is no less than 2,881. These are rated as 'excellent,' ' good,' 'fair,' ' poor,' ' bad.' The three first divisions being grouped as superior analyses are thus worthy of use in petrographical discussion, while the 'poor' and 'bad' analyses are classed as inferior analyses and are considered to be of little or no value. The superior analysis constitutes 64.70 per cent. of the whole, and the inferior analysis, 35.30 per cent.; 'in other words, more than one third of all the analyses which' have been made in the seventeen years included by the collection are not worthy of use for general purposes and a very large part of them are useful for no purpose at all.'

As Dr. Washington points out, petrographers have hitherto not been by any means sufficiently exacting in the standard required in rock analyses. The fact has not generally been recognized that the complete and adequate analysis of a rock is one of the most complex and, in some respects, one of the most difficult problems of analytical science, far beyond the capabilities of a novice and demanding not only chemical knowledge and manipulative skill, but often the exercise of considerable judgment derived from experience in solving the perplexing problems which may present themselves. A very large proportion of all the analyses which can be classed as 'excellent' are the work of the chemists of the United States Geological Survey, which shows the preeminent position which they hold in this branch of the science, while the analyses that are now being made by the Geological Survey of New South Wales are of almost equally high standard.

In the case of each of the superior analyses, Dr. Washington has calculated the norm, which represents in the aggregate a colossal amount of labor, but the results well repay the labor expended to attain them, for all the rock analyses in recent years are thus placed in their proper position in the quantitative system and the suitability of this system of classification is demonstrated. The exact rating and relative value of each analysis is also given. The book may thus be regarded as a sequel to the 'Quantitative Classification of Igneous Rocks' which was reviewed in Science last February. It tests and illustrates in the most elaborate manner the classification therein proposed. One of the most valuable and interesting portions of the work is that dealing with the errors which are likely to vitiate rock analysis, and how they may be avoided, as well as the methods of judging of and testing the accuracy of an analysis when it has been made.

The book is one of the most important contributions to petrography which has been made for many years, and petrographers are deeply indebted to Dr. Washington for the wide lines on which his book is based and the thoroughness with which it is elaborated. It is a work which gives to the chemical aspects of petrography a new significance.

MaGill University.

Frank D. Adams.

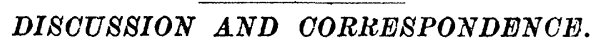

STATEMENTS REGARDING EXCHANGES OFFERED BY THE ALLEGHENY OBSERVATORY LIBRARY.

WHIIE engaged in rearranging and classifying the books and pamphlets of the Allegheny Observatory library we found that many of our important files of the publications of other observatories and scientific societies were broken and incomplete, but that, on the other hand, we possessed many dupli- 
cates. As the same state of affairs exists in many other libraries, it seemed to me that it would be of mutual advantage to ourselves and others to prepare a list giving the names of both our own 'wants' and of the publications we could supply to others, to assist them in completing their files. This was done, and mimeograph copies of the list were distributed to our correspondents and exchanges during the latter part of 1901. "The success of the plan was marked, and for some of the volumes on our list more inquiries and requests were received than we could at that time satisfy. In my annual report for that year (1901, p. 13) I suggested that it might be of value to develop this plan of mutual exchanges into a more comprehensive scheme, having for its basis some large central exchange or ' clearing house' to which all astronomical and scientific libraries might send their duplicate papers and publications, and from which they might in return be able to obtain the volumes or numbers of other publications required to complete their own sets. The suggestion has met with favor from many scientific men, and it is hoped that some arrangement may be made for carrying it into effect at an early date. Some expense is of course involved for correspondence and the publication of exchange lists, but a large part of this could be met by the payment of a small annual fee, if a sufficient number of societies and institutions would join in the development of the plan.

Since the publication of our first exchange list two years ago, we have ourselves received a large number of additional duplicates, partly in exchange, and partly by presentation. The most important gift of the latter class was the one from Miss M. W. Bruce, whose valuable donation of her sister's library to our collection was noted and acknowledged in Scrence (Vol. XV., p. 758, May 9, 1902) and more fully in my annual report for the same year ('Miscellaneous Scientific Papers of the Allegheny Observatory,' No. 12, p. 9). In order to render these additional duplicates available for distribution we have prepared a new exchange list which will be distributed to our regular correspondents, and will also be sent on request to all interested. Correspondents desiring any of the volumes on this list will kindly indicate the titles of publications they are prepared to offer in return, particularly any of those included in our ' wants,' and we will accept all equitable proposals for such exchanges and fill them in the order in which they are received. It is hardly necessary to state that none of the volumes of this list are for sale, but are only offered in exchange.

In order to determine more fully the possible scope and usefulness of the general plan of a central exchange bureau such as has been proposed above, correspondents are requested to give also a list of the publications which they desire to obtain which are not included in our present catalogue, together with a list of all the duplicates in their own library which they would be willing to send to this bureau if it should be established for the purposes indicated. If sufficient interest is manifested and sufficient material offered to meet the mutual 'wants' of those willing to cooperate in this plan, the Allegheny Observatory will undertake to furnish the requisite facilities in the way of storage and packing rooms, and will attend to the assorting, packing and correspondence necessary to effect the exchanges desired on an equitable basis to all parties concerned.

$$
\begin{aligned}
& \text { Alleghen Ý ObSERvatory, } \\
& \text { September, } 1903 .
\end{aligned}
$$$$
\text { F. L. O. Wadsworth. }
$$

\section{TOXIC EFFECT OF O AND OH IONS ON SEEDLINGS} OF INDIAN CORN.

IN a recent article in these columns* on 'The Toxic Effect of $\mathrm{H}$ and $\mathrm{OH}$ Ions on Seedlings of Indian Corn,' the author has apparently overlooked my investigations published some seven years ago. $\nmid$ In the part of the article dealing. with the effect of $\mathrm{H}$ ions upon the seedlings of Indian corn the reader is led to infer that the author is a pioneer.

In my work I tested the effect not only of

* ScIence, 18: 304.1903.

$\uparrow$ Toxic Effect of Dilute Solutions of Acids and Salts on Plants,' Bot. Gaz., 22: 125. 1896. 